\title{
The experiences of women who survived an attempt on their lives by an intimate partner represented a wide spectrum of previous violence and control issues in the relationship
}

Nicolaidis C, Curry MA, Ulrich Y, et al. Could we have known? A qualitative analysis of data from women who survived an attempted homicide by an intimate partner. J Gen Intern Med 2003; 18:788-94.

Q What are the experiences and perceptions of women who survived an attempt on their lives by an intimate partner?

\section{DESIGN}

Qualitative study done in conjunction with an 11 city case-control study.

\section{SETTING}

6 US cities (Baltimore, Maryland; Tampa, Florida; Portland, Oregon; Houston, Texas; Witchita, Kansas; and Kansas City, Missouri).

\section{PARTICIPANTS}

30 women who were 17-54 years of age (47\% European American, $43 \%$ African-American, $10 \%$ Latino or other), had survived a serious attempt on their lives by a current or ex-intimate partner, and were living apart from the perpetrator in a safe environment. Each case was designated as "closed" by the police (arrest made or adjudication).

\section{METHODS}

Women participated in 30-90 minute, audiotaped, semistructured interviews about their relationship with the perpetrator, activities and events preceding the homicide attempt, the event itself, changes since the event, and interactions with helpers (eg, healthcare workers, police, and counsellors). Interviews were transcribed verbatim and analysed by thematic analysis.

\section{MAIN FINDINGS}

20 women had a history of physical or sexual abuse by the perpetrator, 5 described episodes of minor violence, and 5 had no prior history of abuse. Power and control issues were prominent in most relationships: 25 women described examples of stalking, extreme jealousy, physical limitations, or threats of violence. Intensity of control varied from constant romantic gestures (later interpreted as checking up on the victim) to women being prisoners in their own homes.

Women's stories represented a wide spectrum of abuse, defined by the severity of violence and control. At the severe end, women and others were aware of the extreme danger, but were unable to obtain adequate protection. At the low end, it may have been impossible to predict the potential for lethality. The experiences of most women fell somewhere in the middle of the continuum, where despite clues of danger, few discussed the potential risk with service providers.

14 women expressed surprise about the attack. One woman said "I didn't realize what big trouble I was in until I was to the point of where I thought I was going to die."

For 22 women, the attack occurred around the time of a substantial change in their relationship with the perpetrator. Often, women were trying to leave the relationship. Their reasons were usually unrelated to violence, but rather focused on money, drug or alcohol use,

For correspondence: Dr C Nicolaidis, Oregon Health and Science University, Portland, OR, USA. nicolaid@ohsu.edu

Sources of funding: National Institutes of Health; Center for Disease Control; National Institute of Justice; the Collins Foundation. infidelity, possessiveness, or a combination thereof. In 4 instances, men initiated the separation, but became violent when the women began seeing other people or refused to take them back; in 3 instances, the men apparently left the relationship for new partners and/or financial gain.

\section{CONCLUSIONS}

The experiences of women who survived an attempt on their lives by an intimate partner represented a wide spectrum of abuse, defined by the severity of violence and control issues. Most relationships involved a history of abuse and power and control issues.

\section{Commentary}

he qualitative study by Nicolaidis et al was conducted by expert clinicians in the field of intimate partner violence. Data collection and analysis methods were appropriate for the research question. A convenience sample of 30 urban women is justified for a qualitative study of this nature, although some women who reside in suburbia, towns, and farms also experience intimate partner violence and attempted and actual homicide.

The underlying components of intimate partner violence are power and control. An abusive partner purposefully uses power tactics to control the victim and still maintain the relationship. Although most women in the study described tactics of power and control, some were unaware of their partner's power and control until after the attempted homicide.

Contrary to the belief that only women with high Danger Assessment scores are at risk of homicide, this study found that women with Danger Assessment scores of 3-14 had survived attempted homicides. Nicolaidis et al acknowledge that the study did not include same sex couples or adequate representation of Hispanic, Asian, and Native American women.

All women, including those who are pregnant and regardless of their setting and socioeconomic status, should be assessed for intimate partner violence. If intimate partner violence is suspected or confirmed, the Danger Assessment tool should be used to assess the potential for homicide. $41 \%$ of women who have been abused saw a healthcare provider within 1 year before their deaths. ${ }^{~}$ Each contact a nurse has with a woman is an opportunity to assess for intimate partner violence and intervene. A nurse should counsel any woman with a physically abusive or controlling partner about the risk of homicide, especially at the time of a relationship change, regardless of the severity of prior violence or whether or not the relationship is ending because of violence. Interventions include increasing awareness of physical injury or risk of death, development of a safety plan, and providing information on the availability of legal and community resources on intimate partner violence. $^{1}$

Sheila Harvin, RN, MSN, APRN, BC College of Nursing

Prairie View A\&M University Houston, Texas, USA

1 Sharps PW, Koziol-McLain J, Campbell J, et al. Health care providers' missed opportunities for preventing femicide. Prev Med 2001;33:373-80. 